\title{
A Study of Multimedia Application-based Vocabulary Acquisition
}

\author{
Jing Shao ${ }^{1}$ \\ ${ }^{1}$ Bei Jing University of Science and Technology, Yan Qing branch, China \\ Correspondence: Jing Shao, Bei Jing University of Science and Technology, Yan Qing branch, China. E-mail: \\ qiaoqiaozulh@163.com
}

Received: July 5, 2012 Accepted: August 16, 2012 Online Published: August 23, 2012

doi:10.5539/elt.v5n10p202 URL: http://dx.doi.org/10.5539/elt.v5n10p202

\begin{abstract}
The development of computer-assisted language learning (CALL) has created the opportunity for exploring the effects of the multimedia application on foreign language vocabulary acquisition in recent years.

This study provides an overview the computer-assisted language learning (CALL) and detailed a developing result of CALL - multimedia. With the application of constructivism theory, the research explores the use of multimedia software to vocabulary acquisition. It presents a case study that uses survey method to explore the interest level of Chinese college students with the multimedia software they worked with and their attitudes towards multimedia application. Another purpose of the thesis is to examine the effectiveness of multimedia application among Chinese EFL learners.
\end{abstract}

Keywords: vocabulary acquisition, multimedia application, CALL

\section{Review of Computer-assisted Language Learning}

Over the past forty years we have witnessed dramatic changes in the ways of language learning. It is under such multifarious changes that the significant innovation in language education-Computer-Assisted Language Learning (CALL) has come to the age. CALL spans wide ranges of activities in language acquisition - listening, speaking, reading and writing and draws nearly all areas of Information and Communication Technology (ICT). In the process of CALL, language learners can use multimedia software, access foreign language documents on the World Wide Web, and communicate with their teachers, fellow classmates, and native speakers by electronic mail. And the development of computer-assisted language learning has created the need and opportunity for investigating the feasibility of multimedia on vocabulary acquisition. Therefore, many studies have shown that computerized media and a multimedia environment can be helpful for learning foreign language vocabulary. This part sets out to (i) define CALL (ii) development of Lexical CALL programs and (iii) a beneficial result of CALL's development-multimedia.

\subsection{The Definition of CALL}

CALL refers to the use of computer in the teaching and learning of a second or foreign language. CALL may "take advantage of diverse and rapidly expanding spectrum of computer technologies that assist the teaching and learning process." (Richards et al. 1998) Levy (1997) defines CALL more succinctly and more broadly as "the search for and study of applications of the computer in language teaching and learning". This definition is similar to that of Hu Zhuanglin's "CALL refers to the use about a computer in a language teaching and learning program." To sum up, the three definitions include the views help by the majority of modern CALL practitioners.

The field of CALL includes the use of a computer in the language process. CALL applications "include guided drill and practice exercises, computer visualization of complex objects, and computer-facilitated communication between students and teachers" (CAI. 1998). CALL programs aims to teach students in aspects of the language learning process via the medium of computers.

\subsection{Development of Lexical CALL Programs}

Based on vocabulary acquisition theories, researches have described programs they developed for vocabulary acquisition or pointed out guidelines for the design of CALL programs of vocabulary. For example, Goodfellow (1994) suggests that lexical CALL programs need to address the learner's need to build a sizeable L2 mental lexicon; to maximize interactivity in the selection, processing and practice of target words; to promote a deep learning; to support learning processes which focus on structure in the target-word list; to diagnose and help 
modify surface learning approaches; and to generate and record data to learning approaches and outcomes. Nara (1992, 1994) reports on the development of a collocation dictionary for Japanese, emphasizing improved monitoring facilities and presents the design of an on-line dictionary and its research functions.

In addition, there are empirical vocabulary researches in connection with the development of lexical CALL programs. In a research probing L2 learners' use of software systems connected with an on-line dictionary, Bland, Noblitt, Armington and Gay (1990) interpret the form of students' queries as an indication of their stage of lexical development. According to the results of two researches with English as ESL (English as a Second Language) readers, Coady, Magoto, Hubbard, Graney and Mokhtari (1993) suggest that practice with high-frequency vocabulary through computer-assisted learning does benefit reading.

To test the effect of a context-based method to second language vocabulary instruction, Kang (1995) conducted a study with elementary school students who had basic knowledge of the English alphabet and sentence structure. The findings indicated that the students facilitated by the computer-based context method performed dramatically better than any other students in a retention test. This indicated that the presentation of vocabulary with aural, visual and sentence contexts in CALL environments would enhance vocabulary teaching and learning.

\subsection{Multimedia and SLA}

The development of computer-assisted language learning has created the need and opportunity for investigating the effects of multimedia on vocabulary acquisition in recent years. And a great many of studies have shown that computerized media and a multimedia environment can be very helpful for leaning foreign language vocabulary. These encouraging results of the studies have prompted the work described in this paper.

\subsubsection{Combination of Media}

Language teachers often use all the media types that go to make up multimedia in their teaching nowadays. The media types include pictures, sounds, written texts and videos and each of these delivers messages in its own particular way. The particular character of multimedia to language learning is its delivers' ability to exist within the same space. Most people seem to remember more efficiently what they have experienced rather than what they have just read. Memory is also connected with images and multimedia provides opportunities to experience language in a variety of media, each of which can serve to reinforce the other.

\subsubsection{Interactivity}

Strength of computer-delivered materials is their ability to create a situation in which learners working alone or in groups can interact with the learning materials and reference materials. This interactivity makes the learning elements under the learners' control which allows learners as individuals to approach the material with their own actions and agendas.

\subsubsection{Non-judgmental}

Completing works individually in the computer environment is a private affair and any errors or mistakes are often known to the learner. There is no public loss of face at errors on what teachers and classmates may presume to be elementary language and assumed to be already mastered. The areas of learners reluctant to admit to not having understood may be explored by this kind of non-public domain of this learning form. Such alleviation of pressure can also "low affective filters" skills and language learning can be repeated endlessly until the learner who is satisfied with his or her own performance or degree understanding.

\subsubsection{Efficiency}

There are efficiencies in a wide range of learners' time and in quantity of data. Once the multimedia software's contents and navigation is mastered, the software is more efficient for learners to access than other media or combinations of traditional EFL media. The large quantities of instantly accessible indexed data in real world CDs should free time for learning rather than searching. There is also efficiency in features of individual pieces of software that combine reference works (glossaries, dictionaries) and learning materials.

\section{Experimental Study}

\subsection{Research Questions}

The study which started from March and ending in July in 2012 sets out to explore the contribution that multimedia based vocabulary acquisition teaching might offer non-English majors in college English vocabulary classrooms.

Based on the literature review in Part 1 and the purpose of this study, the research goes to ask the following three 
questions:

1. What are the attitudes of the learners' toward the multimedia application for vocabulary acquisition?

2. Does multimedia application facilitate learners' vocabulary acquisition effectively?

3. Can multimedia application be integrated into the teaching curriculum?

The following parts explicitly discuss each of the three questions and their components.

\subsubsection{The Attitudes of the Learners towards the Multimedia Application}

The first question aimed to examine learners' attitudes towards the application and their perceptions of its usefulness for aspects of the vocabulary acquisition. The reason to explore this question first is that it was the most fundamental. If learner reactions to the use of multimedia were negative then this would undermine further research into its effects. The study focused upon learners' attitudes in three aspects:

(1) If learners viewed the application of multimedia as be an enjoyable experience,

(2) Whether the use of multimedia was viewed by learners as being a potentially useful skill development and language learning tool,

(3) If learners regard multimedia as a potentially beneficial tool for self-study?

\subsubsection{The Effectiveness of the Multimedia-based Instruction to Vocabulary Learners}

The research question was designed to provide initial insights of the effectiveness of the multimedia-based instruction to English vocabulary learners'. This is one of the hottest issues in the section of multimedia and SLA of literature review. Quantitative data analyses are used to explore the effectiveness of this multimedia application to the improvement of Chinese ESL learners.

\subsubsection{The Integration of Multimedia Application into the Curriculum}

This research question examined if the application could be integrated into a syllabus and used as a supplement to classroom-based instruction. It explored attitudes of the learners towards the application when they were extrinsically motivated to use it. The question fits into the ideas about the benefits to learners, which are provided by facilitating autonomous language learning, for example Dickinson (1987), Benson and Voller (1996).

\subsection{The Subjects}

80 students participated in this experiment. All of them are freshmen students currently studying in Computer Application University of Science and Technology Beijing. The age of the subjects ranges from 18 to 20 with a mean of 19. They have been learning English as a second language from their junior middle school. It is estimated that according to the New English Curriculum Standard of High School, the subjects have a vocabulary size of 2400 word families. The participants came from two parallel classes, who represented the same level of English on average according to their scores of National Entrance Examination to College. Experiment time is arranged one semester later after they got into the university. One class of 40 students consists of the experimental group and received multimedia application-based instruction. And the other class of 40 students who received the traditional way of word acquisition instruction served as a comparison group.

The instrument applied in the research is the software-I Love English Vocabulary (ILEV), produced by Beijing Wrestler Computer Technology Company Ltd. Currently, it is the widely used vocabulary software program in China. The software is used to assist word input, word retention and word use.

\subsection{Instruments and Procedure}

A great many of books devoted to research methods in SLA have been produced. The field of enquiry into SLA has emerged in the past three decades and only in the last ten years there has been concern to identify which research methods might be most suitable ones. Likewise in multimedia research, scholars have been focused on outlining the kinds of research methodologies which might be productive as practitioners' awareness of the nature of the questions research into CALL needs to be answered has become more concerned with.

\subsection{The Control of Irrelevant Variables}

According to the scores of the students' recruit examination, two classes were chosen respectively as the control group and the experimental group in the research. Therefore, there is no significant difference between the two groups in their academic background. The control group received the traditional way of word acquisition instruction while the experimental group received multimedia application-based teaching. 


\section{Results of the Study}

In this part, the researcher will present the statistic description of the experimental test so as to examine the attitudes of Chinese college students toward multimedia application and their interest level with the multimedia software they worked with. SPSS (Statistics Package of Social Science) software is made use of in this research to facilitate the numeric calculation, and Paired Samples T-test is applied to this research.

\subsection{Students'Attitudes towards the Multimedia Application}

The general attitudes is showed on the data from the questionnaire, attitudes as to possible learning efficacy and attitudes to the application's potential as a self-study tool. The percentage form of the results is presented in Tables 1 below.

Table 1 shows that students' general attitudes towards using the multimedia application were significantly favorable. According to the responses to the statements, more than $80 \%$ reacted positively and the application's "usefulness" "ease" and "fun" characteristics typifies the most positive reactions.

Table 1. Subjects' general attitudes o the multimedia application in percentage

\begin{tabular}{llllll}
\hline $\begin{array}{l}\text { Attitudinal } \\
\text { Statement }\end{array}$ & $\begin{array}{l}\text { Strongly } \\
\text { Agree }\end{array}$ & Agree & Disagree & $\begin{array}{l}\text { Strongly } \\
\text { Disagree }\end{array}$ & No Reply \\
\hline Useful & 48.2 & 43.5 & 5.2 & 0 & 3.1 \\
\hline Simple & 35.7 & 52.3 & 6.2 & 2.9 & 2.9 \\
\hline Fun & 32.7 & 39.3 & 22.4 & 2.4 & 3.2 \\
\hline Easy & 30.9 & 42 & 22.3 & 2.7 & 2.1 \\
\hline Motivating & 24.5 & 49.3 & 19.8 & 2.7 & 3.7 \\
\hline Interesting & 31.8 & 48.6 & 11.3 & 3.6 & 4.7 \\
\hline A waste of time & 1.8 & 0.9 & 5.6 & 45.8 & 45.9 \\
\hline Complicated & 1.9 & 6.5 & 11.2 & 51.4 & 29 \\
\hline Not enjoyable & 0.9 & 13 & 51.5 & 32.7 & 1.9 \\
\hline Not motivating & 3.7 & 2.9 & 12.1 & 49.6 & 31.7 \\
\hline Boring & 3.9 & 2.7 & 12.1 & 48.6 & 32.7 \\
\hline Difficult & 0 & 2.6 & 14.2 & 49.6 & 33.6 \\
\hline
\end{tabular}

\subsection{The Integration of Multimedia Application into the Curriculum}

\subsubsection{Rationale for the Integration of the Multimedia Application into the Curriculum}

A decisive factor in the decision to merge multimedia-based autonomous study into the curriculum was the positive responses gained from the research reported in Chapter Three. To successfully integrate any computer-based element into a language learning program requires matching appropriate software and hardware provision to pedagogically sound movies. Likewise, the innovation needs to have high learner face-validity (White, 1998) with learners being able to perceive this as relevant to their learning objectives. The evidence from the previous chapter showed that the conditions would be met by such an innovation. There are few studies which explore on such a curriculum innovation with multimedia.

There were a few of other localized factors of the specific learning context which gave further reasons for the integration of the multimedia applications into the curriculum. The restrictions of the class contact time meant that guided practice in enhancing vocabulary acquisition was also limited. Only indirectly measurable, an important intended outcome was that all learners would have undertaken individualized and guided practice in vocabulary acquisition and their vocabulary acquisition and store of language may have increased through interacting with the language input.

\subsubsection{Attitudes towards the Multimedia Applications' Integration into Curriculum}

In response to the third research question 'Whether multimedia application could be integrated into the teaching curriculum', data collected from the questionnaire indicated that the study didn't confirm the hypotheses. Hypothesis three that the subject would have positive attitudes to the application of the multimedia as a formal important part of their curriculum was not confirmed by the data of the questionnaire. $80 \%$ of the students didn't agree to integrate multimedia based instruction into their curriculum although it has proved to be effective in 
enhancing learners' vocabulary acquisition. The reason is as follows.

Firstly, it is very different with the traditional teaching methods and sometimes it could be a waste of time because of the limitations of software and the technological factors. Secondly, with the effectiveness in some ways of the traditional teaching method, students have not got used to the new teaching method. Thirdly, the lacks of required skills of computer operating exist in many students. Last but not the least important, the lack of motivation can be an important factor.

The researcher believes that the attitudes of the students may change some day in the future, but as not all the classrooms are equipped with the multimedia tools, the existing conditions for promoting multimedia based instruction can be a great obstacle.

\section{Conclusion}

All the general overview of the findings of this research and the implications for multimedia application in vocabulary acquisition and suggestions for further research on fruitful areas are presented in detail in this part.

\subsection{Summary of the Study}

The study aims to examine the application of multimedia courseware to vocabulary acquisition. After the reviewing of the study relevant theories and the multimedia as a result of the development of CALL, the study presents a case study which uses some survey methods to explore the interest level of Chinese college students with multimedia software they work with and the attitudes they hold towards multimedia application. Another purpose of the study is to explore the effectiveness of multimedia application among Chinese EFL learners. The intention of the thesis is to give reflections on switching of teacher's role from that of traditional classroom to multimedia environment.

An experimental study of multimedia application was implemented with 80 participants for about one semester. After qualitative and quantitative data analysis, we found the result of the study is encouraging. Learners held highly positive attitudes to the application of the multimedia software. And there was also clear evidences showing the effectiveness of the application of multimedia to the development of vocabulary acquisition. Nevertheless, the integration of the multimedia application into the curriculum was not successfully confirmed for the following reasons: firstly, there are great differences between the computer-assisted learning process and the traditional way and sometimes it can be a waste of time because of the limitations of the software and the technological factors. Secondly, the traditional teaching method is effective to some extent and for some students. Thirdly, a great number of students are confronted with the problem that they are lack of required skills of computer operating. Last but not the least important, the lack of motivation also can be a decisive factor. The writer believes that the attitudes of the learners will be changed some day in the future, but promoting multimedia based instruction is proved to be a great obstacle for not all the classrooms are equipped with the multimedia tools.

\subsection{Limitations of the Study}

The study tried to explore vocabulary acquisition in a multimedia environment in a Chinese context. Because of the low reliabilities, the findings of the study are tentative. Firstly, the findings are based on a small group of subjects and the length of training makes it impossible beyond the conditions descried in this thesis without replication of the experiment to generalize the findings of the study. In addition, the researcher's experience in such a study makes certain kinds of investigation impossible. Secondly, because all the subjects' names were required to be written down on the questionnaires, the reliability of the questionnaire may weak for some students' reluctance.

Some wider implications could be affected by the limitations of this study. The data in this thesis show strongly favorable to the use of this program. It is attentive to be cautious about the data which is based on the learners' evaluations of multimedia. The data's reliability and validity might have been compromised by the sample telling you what they think you want to hear; therefore interpretations of such strong evaluations should be based on other evidence.

The results of the study are positive, but they measure reactions after only one supervised application. Subjects may become less enthusiastic after repeated use of the multimedia application, thus, further studies may need to value attitudes over a period of time. If multimedia had replaced teacher contact time and became a mandatory part of the curriculum, attitudes might have been less positive. There may also have an effect that enhances the strength of positive feeling.

The study also focused on only one multimedia program thus it is impossible for this study to include all 
multimedia language learning applications.

\subsection{Suggestions for Further Research}

The limitations of the present study leave room for alterations and replications in the design of the study. And the findings of this study also leave room for further investigation in designing and implementing multimedia application programs.

\section{References}

Benson, P., \& Voller, P. (1996). Autonomy and Independence in Language Learning. Harlow: Longman.

Bensoussan, \& Laufer, B. (1984). Assessing the effectiveness of monolingual, bilingual, and production of new words. Modern Language Journal, 81, 189-196.

CAI. (1998). Encarta Encyclopedia 99 [CD-ROM]. New York: Microsoft.

Coady, J. (1997). L2 vocabulary acquisition through extensive reading. In J. Coady, \& T. Huckin (Eds), Second Language Vocabulary Acquisition. Cambridge: Cambridge University Press.

Dickinson, L. (1987). Self Instruction in Language Learning. Cambridge: Cambridge University Press.

Goodfellow, R. (1995). CALL Programs for Vocabulary Instruction. Computer Assisted Language Learning Journal, 8(2/3), 205-226. http://dx.doi.org/10.1080/0958822940080206

Kang, S. H. (1995). The Effects of a Context-embedded Approach to Second-language Vocabulary Learning. System, 23, 43-55. http://dx.doi.org/10.1016/0346-251X(94)00051-7

Kearsley, G. (1999). Constructivist Theory.Retrieved from http://www.gwu.Edu/tip/index.html

Marlowe, B. A., \& Page, M. L. (1998). Creating and Sustaining the Constructivist Classroom. California: Crowin Press.

Mccarthy, B. (1996). Fully Integrated CALL: Mission Accomplished. ReCALL, 8(2), 17-34. http://dx.doi.org/10.1017/S0958344000003542

Merrill, P. F., Hammons, K. et al. (1996). Computers in Education. Boston, MA: Allyn \& Bacon.

Murray, J. (1991). Knowledge Machines: Language and Information in a Technological Society. Harlow: Longman.

Nara, H. (1992). Visual Salience as a Search Category in a Kanji Dictionary in Interactive Japanese: Understanding Written Japanese. System, 20, 75-91. http://dx.doi.org/10.1016/0346-251X(92)90009-R

Nara, H. (1994). Improved Delivery of Lexical Information in a computer-assisted Reading Instruction Program. CALICO Journal, 12(1), 19-36.

Nation, I. S. P. (1990). Teaching and Learning Vocabulary. New York: Heinle \& Heinle Publishers.

Levy, M. (1997). Computer-Assisted Language Learning: Context and Conceptualization. Clarendon paper backs.

Piaget, J. (1970). Structuralism. New York: Basic Books.

Richards, J. C. et al. (1998). Longman dictionary of language teaching and applied linguistics. London: Longman.

Vander Zanden. J. W., \& Pace, A. J. (1984). Educational Psychology in Theory and Practice. Random House, Inc. USA.

White, R.V. (1998). The ELT Curriculum. Oxford: Blackwell. 